Research Article

\title{
Elastic-Viscoplastic Constitutive Model of Soil under Cyclic Loading
}

\author{
Yuan Ma $\mathbb{D}^{1},{ }^{1}$ Hua Liang, ${ }^{2}$ Yongxue You, ${ }^{3}$ Weiguang Zhang $\mathbb{D}^{1},{ }^{1}$ Limin Guo, ${ }^{3}$ Jianwei Fan, \\ and Zhihui $\mathrm{Cao}^{3}$
}

${ }^{1}$ School of Transportation, Southeast University, Nanjing 211189, China
${ }^{2}$ Jiangxi Transportation Investment Group Co., Ltd., Jiangxi 330025, China
${ }_{3}^{3}$ Luoyang Tecfure Municipal Engineering Co., Ltd., Luoyang 471935, China

Correspondence should be addressed to Weiguang Zhang; wgzhang@seu.edu.cn

Received 23 May 2021; Accepted 9 August 2021; Published 1 September 2021

Academic Editor: Jian Ji

Copyright (c) 2021 Yuan Ma et al. This is an open access article distributed under the Creative Commons Attribution License, which permits unrestricted use, distribution, and reproduction in any medium, provided the original work is properly cited.

The creep problems are often involved in soil under cyclic loading, and its behaviors of soil under cyclic loading sparks many arguments in current research field. To propose one new model to demonstrate these creep behaviors of soil under cyclic loading, the cyclic loading was simplified equivalently, and the elastic-viscoplastic model (EVPM) for soil under cyclic loading was established based on the Bingham model. The yield criterion for soil under cyclic loading with constant amplitude was proposed following the simplified load. A constitutive equation based on the EVPM was constructed by using the flow criterion related to the yield criterion. Meanwhile, the parameters of EVPM were identified and discussed. In addition, the case analysis of the EVPM was also performed. The results indicate that the stable and destructive creep behaviors of soil under cyclic loading could be well described by the recommended EVPM, and the obtained parameters in the model exhibited a clear regularity with the increase of dynamic stress amplitude. Besides, the established model could be selected to predict the stable and destructive creep behavior of soil under cyclic loading.

\section{Introduction}

In geotechnical engineering, the building foundations often involves creep behaviors of soil under cyclic loading, such as earth dams under the conditions of cyclical changes in water level of reservoir and subgrade soil under traffic load and tunnels under high-speed railway load. The strength and creep characteristics of soil under cyclic loading are critical to the safety of engineering [1]. Under high-cycle stress, with the increase of loading time, the creep rate of soil becomes bigger; thus, the excessive deformation is caused. Meanwhile, the creep behavior will also occur under low-cycle stress. Therefore, the research concerning the creep characteristics of soil under cyclic loading has certain theoretical significance for the long-term stability evaluation as well as design of geotechnical engineering.

The creep behaviors of soil under cyclic loading are divided into stable, critical, and destructive creep (Figure 1) in accordance with the $\varepsilon(N)-N$ curves of soil under cyclic loading [2-9]. When the peak deviatoric stress $\sigma_{1 \max }-\sigma_{3}$ of cyclic loading is less than the critical dynamic stress $\sigma_{\text {cr }}$ of soil, the creep rate soil is faster at the initial stage of loading; as the loading time is prolonged, the strain does not increase but stabilizes; in this case, the creep behavior of soil belongs to stable creep. When the peak deviatoric stress $\sigma_{1 \text { max }}-\sigma_{3}$ of cyclic loading is near the critical stress value $\sigma_{\mathrm{cr}}$ of soil, the strain of soil sometimes increases and sometimes decreases with the increase of cyclic times $N$. In this case, the creep behavior of soil belongs to critical creep. When $\left(\sigma_{1 \max }-\sigma_{3}\right)>\sigma_{\mathrm{cr}}$, the creep rate of soil increases until the soil is destroyed with the increase of $N$; at this time, the creep behavior of soil belongs to destructive creep behavior. Sometimes, the destructive creep behaviors show three creep stages of obvious constant speed, deceleration, and acceleration (Figure 2).

At present, many scholars have carried out a lot of research on the models which describe the strain accumulation curves of soil shown in Figures 1 and 2. Many achievements 


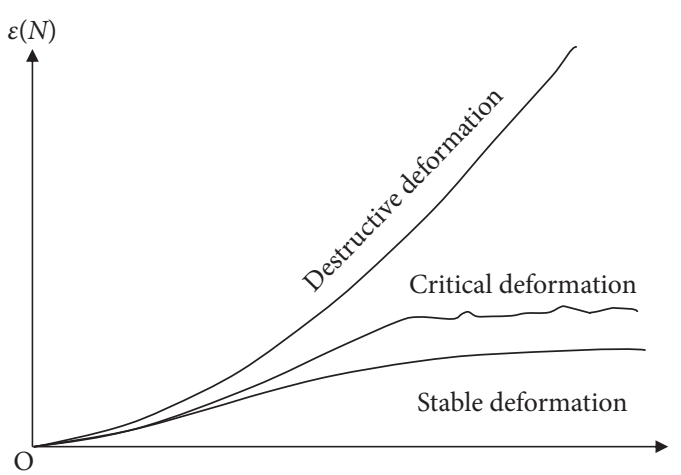

Figure 1: Typical creep curves of soil under cyclic loading.

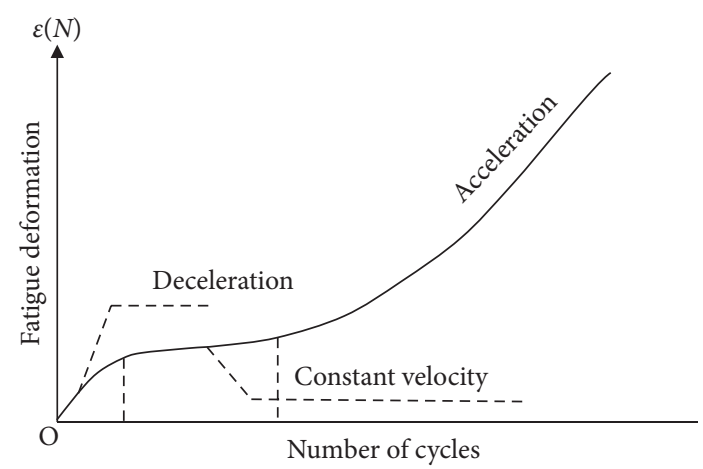

Figure 2: Three-stage creep curve of soil under cyclic loading.

have been made in these studies. There are two main aspects in the study of soil plastic cumulative model under cyclic loading, i.e., theoretical models and mathematical empirical models. The theoretical models mainly include plastic accumulation energy model [10], rheology theory model [11-14], modified Cambridge model [15], and HCA model [16]. Mathematical empirical models include stress-strain hyperbolic model [17], exponential model [18], modified hyperbolic model on the basis of hyperbolic model and exponential model [19], grey theory model [20], and semiempirical and semitheoretical model [21].

Although many constitutive models for soil under cyclic loading have been developed, many existing models cannot well reflect the plastic creep characteristics of soil under cyclic loading. Therefore, the relevant research still needs to be strengthened. In this paper, according to the existing theory, the cyclic loading was simplified equivalently. A dynamic yield criterion of soil was proposed based on the simplified load. A new constitutive equation based on the improved Bingham model was established by using the flow criterion related to the dynamic yield criterion. Meanwhile, the creep constitutive equation was obtained. The parameters of the model were identified and application analysis was also conducted on the proposed model.

\section{Creep Theory of Soil under Cyclic Loading}

2.1. Cyclic Loading and Simplified Load. In engineering, the most frequently encountered types of cyclic loading are sine- wave, cosine-wave, and rectangle- and triangular-wave cyclic loading. However, the rectangular- and triangular-wave cyclic loading can be transformed into sine-wave or cosinewave cyclic loading by Fourier transformation. Therefore, in this study, the sine-wave cyclic loading equation (1) is taken as an example to study the creep behavior of soil under cyclic loading:

$$
\sigma(t)=\sigma_{\mathrm{av}}+\left(\frac{\sigma_{d}}{2}\right) \sin (\omega t)
$$

where $\sigma_{\mathrm{av}}$ is the vibration center of cyclic loading, that is, the average value of cyclic loading, $\sigma_{d}$ is the stress double amplitude of cyclic loading, $\omega$ is the angular frequency of cyclic loading, $\omega=2 \pi f$ ( $f$ is loading frequency), and $t$ is the time of loading.

For the sake of simplicity of the study [14], the cyclic loading (see equation (1)) acting on the soil was simplified into equation (2). However, the confining pressure was not considered in the simplified load:

$$
\sigma^{\mathrm{eq}}=\sigma_{\mathrm{av}} \exp \left[\left(\frac{\sigma_{\mathrm{max}}-\sigma_{\mathrm{cr}}}{\sigma_{\mathrm{cr}}}\right) f\right],
$$

where $\sigma_{\max }$ is the upper limit of cyclic stress and $\sigma_{\mathrm{cr}}$ is the critical dynamic stress of soil.

In accordance with equation (2), when $\sigma_{\max }>\sigma_{\mathrm{cr}}$, the simplified load $\sigma^{\text {eq }}$ is larger than the average value $\sigma_{\text {av }}$ of cyclic loading; in this case, the destructive creep of soil will appear. When $\sigma_{\max }<\sigma_{\text {cr }}$ and $\sigma^{\mathrm{eq}}<\sigma_{\mathrm{av}}$, in this case, the stable creep of soil will appear. For equation (2), the equivalent stress $\sigma^{\text {eq }}$ increases with increasing frequency $f$ and $\sigma_{\max }$ of cyclic loading acting on soil. Although equation (2) was treated as a static form load on the surface, the properties of cyclic loading in essence can be reflected by it.

When we consider the confining pressure, the problem is studied under the state of principal stress. It is assumed that the direction of cyclic loading is consistent with the direction of the maximal principal stress $\sigma_{1}$; then, the cyclic loading under confining pressure can be written as

$$
\sigma_{1}(t)=p_{\mathrm{c}}+\sigma_{\mathrm{st}}+\left(\frac{\sigma_{d}}{2}\right) \sin (\omega t)
$$

where $p_{\mathrm{c}}$ is confining pressure and $\sigma_{\mathrm{st}}$ is static deviatoric stress.

Based on the idea of equation (2), when we take the influence of confining pressure on creep behavior into consideration, the deviatoric stress of soil subjected to the cyclic loading shown in equation (3) can be equivalently simplified as

$$
\sigma_{1}^{\mathrm{eq}}-\sigma_{3}=\sigma_{\mathrm{av}} \exp \left\{\left[\frac{\left(\sigma_{1 \max }-\sigma_{3}\right)-\sigma_{\mathrm{cr}}}{\sigma_{\mathrm{cr}}}\right] g(f)\right\},
$$

where $\sigma_{\mathrm{av}}$ is the average value of the deviatoric stress of cyclic loading, namely, the vibration center value of the load $\sigma_{1}(t)-\sigma_{3}, \sigma_{1 \max }$ is the upper limit of cyclic loading, $\sigma_{1 \max }=p_{\mathrm{c}}+\sigma_{\mathrm{st}}+\sigma_{d} / 2, \sigma_{\mathrm{cr}}$ is the critical strength of soil under confining pressure, only the destructive creep behavior appears, will the maximum stress value determined by the $\left[\sigma_{1}(t)-\sigma_{3}\right]-\varepsilon(N)$ curve of soil under cyclic loading 
occur, $\sigma_{3}$ is the confining pressure acing on soil, and $g(f)$ is a function of frequency.

In equation (4), $0<\left\{\left[\left(\sigma_{1 \max }-\sigma_{3}\right)-\sigma_{\mathrm{cr}}\right] / \sigma_{\mathrm{cr}}\right\}<1$; if equation (4) can be used to reflect the characteristic of cyclic loading, then there must be $0 \leq g(f)<1$. If the $g(f)$ value is too large, the simplified stress will exceed $\sigma_{1 \max }$; as a result, the simplified stress is not consistent with the actual situation. For this reason, the frequency function in equation (4) is determined by

$$
g(f)=\frac{f}{10^{n}}
$$

where $n$ is an integer and its value is determined according to the following procedure.

With relation $0 \leq g(f)<1$, if cyclic loading is with different frequencies in the experiment when testing, the parameter $n$ should satisfy

$$
0 \leq \frac{f_{\max }}{10^{n}}<1,
$$

where $f_{\max }$ is the maximum frequency value of cyclic loading used during testing, and it is determined by

$$
f_{\max }=\max \left\{f_{1}, f_{2}, \ldots, f_{n}\right\} \text {, }
$$

where $f_{1}, f_{2}, \ldots, f_{n}$ are the frequency values of cyclic load used during the test.

From equation (6), it is well known that $n \geq 0$ and $n \geq \lg f_{\text {max }}$. When $\lg f_{\text {max }}<0, n$ value is 0 . When $\lg f_{\text {max }}>0, n$ rounds up to the nearest multiple of $\lg f_{\max }$.

According to equation (4), it is obvious that when the peak deviatoric stress of cyclic loading $\left(\sigma_{1 \max }-\sigma_{3}\right)>\sigma_{\mathrm{cr}}$ is larger than $\sigma_{\mathrm{cr}}$, the equivalent deviatoric stress $\sigma_{1}^{\mathrm{eq}}-\sigma_{3}>\sigma_{\mathrm{av}}$, the destructive creep of soil will appear, and when $\left(\sigma_{1 \max }-\sigma_{3}\right)<\sigma_{\mathrm{cr}}$, the equivalent deviatoric stress $\sigma_{1}^{\mathrm{eq}}-\sigma_{3}<\sigma_{\mathrm{av}}$, and the destructive creep of soil will not appear.

\subsection{Dynamic Yield Criterion for Soil under Cyclic Loading}

2.2.1. Establishment of Dynamic Yield Criterion. Because of the structural behavior and porosity of soil, the plastic volume and shear strain will occur when soil is subjected to cyclic loading. The creep behavior of soil under cyclic loading is related not only to its stress state but also to the characteristics of cyclic loading. Consequently, the dynamic yield function of soil under cyclic loading can be established in accordance with the equivalent load as follows:

$$
F\left(I_{1 \mathrm{eq}}, J_{2 \mathrm{eq}}, \phi_{\mathrm{cq}}, \phi_{\mathrm{eq}}, \sigma_{\mathrm{av}}\right)=\alpha_{\mathrm{eq}} I_{1 \mathrm{eq}}+2 \sqrt{J_{2 \mathrm{eq}}}-K_{\mathrm{eq}}-\frac{1}{\sqrt{3} \sigma_{\mathrm{av}}}
$$

where $J_{2 \mathrm{eq}}$ is the second invariant of equivalent stress deviator, $\sqrt{J_{2 \mathrm{eq}}}=\sqrt{1 / 6\left[\left(\left[\sigma_{1}\right]_{\mathrm{eq}}-\sigma_{2}\right)^{2}+\left(\sigma_{2}-\sigma_{3}\right)^{2}+\left(\sigma_{3}-\left[\sigma_{1}\right]_{\mathrm{eq}}\right)^{2}\right]}$,

$I_{1 \text { eq }}$ is first invariant of equivalent stress tensor, $\alpha_{\text {eq }} I_{1 \text { eq }}$ reflects the volumetric strain under cyclic loading, that is, the expansibility of soil, $\alpha_{\text {eq }}$ is the equivalent influence coefficient of volume strain of soil, and $K_{\mathrm{eq}}$ is the equivalent strength eigenvalue of soil under cyclic loading.

The influence of hydrostatic pressure on the plastic volumetric strain of geomaterials is considered by $\alpha I_{1 \text { eq }}$ of this criterion, and the influence of stress deviator on the shear strain of soil is reflected by $\sqrt{J_{2}}$.

The parameters $\alpha_{\text {eq }}$ and $K_{\text {eq }}$ in equation (8) is taken as the equivalent form of $\alpha$ and $K$ of Druker-Prager criterion [22], i.e.,

$$
\begin{aligned}
& \alpha_{\mathrm{eq}}=\frac{\sin \phi_{\mathrm{eq}}}{\sqrt{3} \sqrt{3+\sin ^{2} \phi_{\mathrm{eq}}}}, \\
& K_{\mathrm{eq}}=\frac{\sqrt{3} c_{\mathrm{eq}} \cos \phi_{\mathrm{eq}}}{\sqrt{3+\sin ^{2} \phi_{\mathrm{eq}}}}
\end{aligned}
$$

where $\phi_{\text {eq }}$ is equivalent internal friction angle of soil under cyclic loading and $c_{\mathrm{eq}}$ is the equivalent cohesion of soil under cyclic loading.

2.2.2. The Definition and Meaning of $\varphi_{e q}$ and $c_{e q} . \varphi_{\mathrm{eq}}$ and $c_{\mathrm{eq}}$ are two dynamic indicators of soil under cyclic loading, that is, two strength indexes for soil resistance to destruction, which can be calculated in accordance with the Mohr-Coulomb criterion. The calculation process is as follows. Calculate the equivalent stress $\sigma_{1}^{\text {eq }}$ of soil in the critical state according to equation (4) and then equivalent the Mohr-Coulomb diagram plotted, as shown in Figure 3. Finally, the $\varphi_{\mathrm{eq}}$ and $c_{\mathrm{eq}}$ values can be obtained from Figure 3 and also be solved by equation (10) according to the test data under two different stress states:

$$
\sin \phi_{\mathrm{eq}}=\frac{\sigma_{1 \mathrm{eq}}-\sigma_{3}}{\sigma_{1 \mathrm{eq}}+\sigma_{3}+2 c_{\mathrm{eq}} \cot \phi_{\mathrm{eq}}} .
$$

\section{Elastic-Viscoplastic Constitutive Equation for Soil under Cyclic Loading}

3.1. Elastic-Viscoplastic Model Based on the Bingham Model. The Bingham model is composed of elastic element and ideal viscoplastic body in series, which cannot reflect the nonlinear creep behavior characteristics of geotechnical materials [23]. In order to describe the nonlinear creep behavior of soil under cyclic loading, a modified Bingham constitutive model (see Figure 4) is proposed by replacing the constant elastic and viscous elements in the Bingham model with nonlinear elements. A three-dimensional elasto-viscoplastic fatigue model (EVPM) for soil was established on the basis of the improved Bingham model. In Figure $4, G(N)$ is the elastic shear coefficient and $\eta(N)$ is viscoplastic shear coefficient.

3.1.1. Elastic Element. The relationships between dynamic strength, dynamic shear modulus, and the damping ratio of geomaterials under cyclic loading and the number of cycles $N$ (or loads time $t$ ) were studied by many researchers such as Lai Xilei [24] and Mu Kun [25]. These results show that the 


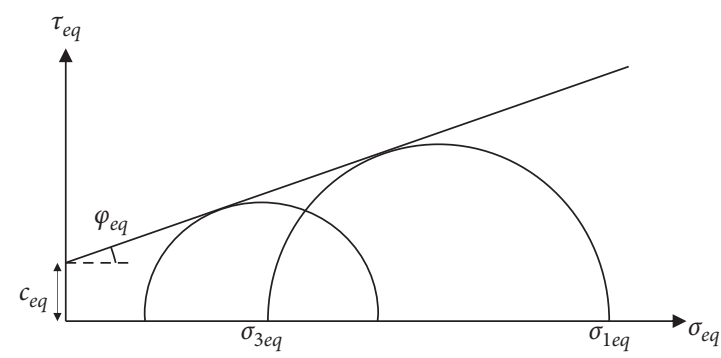

Figure 3: Equivalent Mohr-Coulomb diagram.

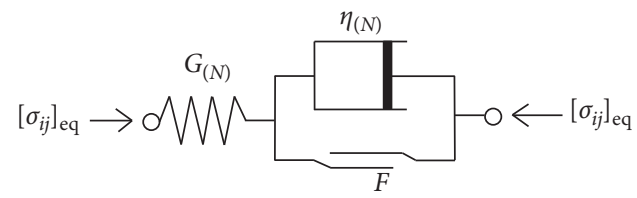

FIgURE 4: Improved Bingham fatigue model.

dynamic parameters of geotechnical materials decrease with the increase of $N$ (or loading time $t$ ), and most of them decay in the form of exponential functions. For this reason, it is assumed that the elastic shear fatigue coefficient $G(N)$ in the model, shown in Figure 4, is

$$
G(N)=G_{0} \exp \left[-\lambda\left(\frac{N}{f}\right)^{\lambda}\right]
$$

where $G_{0}$ is the initial value of shear coefficient of elastic element, and its physical dimension is stress, and $\lambda$ is a dimensionless parameter, which is used to reflect the change rule of elastic shear coefficient and the strain rate of soil at the stable creep stage, and it can be determined by test data and $\lambda>0$.

3.1.2. Viscous Element. Based on fractional calculus theory, the fractional element is defined and the fractional Kelvin-Voigt rheological model is constructed by Guo Jiaqi et al. [26]. It is found that the strain compliance $J(t)$ of the fractional element is proportional to the rheological time $t^{\beta}$, in which $\beta$ is a constant and $t$ is rheology time. Schiessel et al. [27] gave the strain compliance of the fractional unit proportional to $t^{\beta}$ by considering the time accumulation of viscous elements in the Kelvin model and constructed a fractional rheological constitutive equation by defining fractional units according to fractional derivative. From the above, it can be assumed that the coefficient $\eta(N)$ of the viscous element in the model, shown in Figure 4 , is

$$
\begin{aligned}
\eta(N) & =\eta_{0} t^{1-n} \\
& =\eta_{0}\left(\frac{N}{f}\right)^{1-n},
\end{aligned}
$$

where $n$ is the strain rate parameter for soil destructive creep behavior, $n \neq 1, \eta_{0}$ is an initial value of viscoplastic element, and $\eta_{0} \neq 0$, its physical dimension is stress.time $n$.
3.2. Constitutive Equation for Stable Creep of Soil under Cyclic Loading. When the stable creep behavior occurs, the creep behavior is described by the nonlinear elastic element in the model, as shown in Figure 4. At this time, the model is degenerated to the classical nonlinear elastic model. According to the basic theory of elastic mechanics, the state equation of elastic element can be expressed as

$$
\left\{\begin{array}{l}
S_{i j}^{\mathrm{eq}}=2 G(N) e_{i j}^{\mathrm{e}}(N), \\
\varepsilon_{m}=\frac{1}{3 K(N)} \sigma_{m}^{\mathrm{eq}},
\end{array}\right.
$$

where $S_{i j}^{\mathrm{eq}}$ is the equivalent stress deviator, $S_{i j}^{\mathrm{eq}}=\sigma_{i j}^{\mathrm{eq}}-\sigma_{m}^{\mathrm{eq}} \delta_{i j}$ ( $\delta_{i j}$ is Kronecker delta mark), $e_{i j}^{\mathrm{e}}(N)$ is the strain tensor of elastic element, $\sigma_{m}^{\mathrm{eq}}$ is equivalent average stress, $\varepsilon_{m}$ is the volumetric strain, and $K(N)$ is the fatigue bulk modulus of soil, assuming that its variation law is the same as that of $G(N)$; accordingly, we have

$$
K(N)=K_{0} \exp \left[-\lambda\left(\frac{N}{f}\right)^{\lambda}\right]
$$

where $K_{0}$ is the initial value of volume coefficient.

When the cycle number of load is $N$, the strain of the elastic element is

$$
\varepsilon_{i j}^{\mathrm{e}}(N)=\left(\frac{1}{2 G_{0}} S_{i j}^{\mathrm{eq}}+\frac{\sigma_{k k}^{\mathrm{eq}} \delta_{i j}}{9 K_{0}}\right)\left(\frac{1}{\exp \left[-\lambda(N / f)^{\lambda}\right]}\right),
$$

where $\sigma_{k k}^{\mathrm{eq}}$ is the first invariant of the stress tensor.

As indicated in equation (15), we have

(1) When the cycles' number $N \longrightarrow 0$ of cyclic load $\sigma_{1}(t), \Delta \varepsilon_{i j}^{\mathrm{e}}(N) \longrightarrow\left(1 / 2 G_{0}\right) S_{i j}^{\mathrm{eq}}+\left(1 / 9 K_{0}\right) \sigma_{k k}^{\mathrm{eq}} \delta_{i j}$, i.e., which is the transient elastic strain.

(2) When $N \longrightarrow \infty, \Delta \varepsilon_{i j}(N)$ is directly proportional to the exponential function $\exp \left[\lambda(N / f)^{\lambda}\right]$. When 
different $\lambda$ are chosen, the stable creep behavior of soil is reflected.

3.3. Constitutive Equation for Soil Destructive Creep Behavior. When the destructive creep of soil occurs, in the model shown in Figure 4, the soil strain is composed of elastic and viscoplastic strain. When the cycle number of cyclic loading is $N$, soil strain is

$$
\varepsilon_{i j}(N)=\varepsilon_{i j}^{\mathrm{e}}(N)+\varepsilon_{i j}^{\mathrm{vp}}(N) .
$$

In accordance with the basic principle of rheological mechanics, the viscoplastic flow rate in equation (16) can be determined by [28].

$$
\dot{\varepsilon}_{l, \mathrm{vp}}(t)=\frac{1}{\eta_{M}}\langle\varphi(F)\rangle \frac{\partial Q}{\partial \sigma},
$$

where $\eta_{M}$ is viscoplastic flow coefficient and $\langle\varphi(F)\rangle$ is calculated by equation (18). The main forms of $\varphi(F)$ are equations (19) and (20), respectively [29]:

$$
\begin{aligned}
\langle\varphi(F)\rangle & = \begin{cases}0, & (F<0), \\
\varphi(F), & (F>0),\end{cases} \\
\varphi(F) & =F^{b} \cdot(b \geq 1), \\
\varphi(F) & =\exp F-1 .
\end{aligned}
$$

The plastic strain of soil under cyclic loading can be determined by equation (17). With $t=N / f$ and $\mathrm{d} t=\mathrm{d} N / f$, the viscoplastic flow rate of viscoplastic bodies in the model shown in Figure 4 can be written as

$$
\begin{aligned}
\dot{\varepsilon}_{i j}^{\mathrm{vp}}(t) & =f \dot{\varepsilon}_{i j}^{\mathrm{vp}}(N) \\
& =\frac{1}{\eta(N)}\langle\varphi(F)\rangle \frac{\partial Q}{\partial \sigma_{i j}},
\end{aligned}
$$

where $\dot{\varepsilon}_{i j}^{\mathrm{vp}}(t)$ is the viscoplastic flow rate of viscoplastic bodies in the model at time $t, \dot{e}_{i j}^{\mathrm{vp}}(N)$ is the viscoplastic strain rate of the viscoplastic body in the model shown in Figure 4 when the number of cycles is $N, F$ is the dynamic yield function of soil, and $Q$ is the dynamic plastic potential function of soil.

$\varphi(F)$ is calculated by equation (19) in this article, and taking $b$ as 1 in processes of calculating, then equation (17) is expressed as

$$
\varphi(F)=F
$$

If the flow rule related to yield criterion is adopted, then $F=Q$. When the destructive creep behavior occurs, the strain of viscoplastic body in the model can be obtained by integrating equation (22) as follows:

$$
\varepsilon_{i j}^{\mathrm{vp}}(N)=\frac{1}{\eta_{0} n} F \frac{\partial F}{\partial \sigma_{i j}}\left(\frac{N}{f}\right)^{n} .
$$

When the destructive creep behavior occurs, it is assumed that the main deformation is plastic deformation. Without considering the volume strain and instantaneous elastic strain, the constitutive equation of elastic-viscoplastic fatigue based on the model shown in Figure 4 can be obtained from equations (15) and (23) as follows:

$$
\Delta \varepsilon_{i j}^{\mathrm{p}}(N)=\frac{1}{2 G_{0} \exp \left[-\lambda(N / f)^{\lambda}\right]} S_{i j}^{\mathrm{eq}}+\frac{1}{\eta_{0} n} F \frac{\partial F}{\partial \sigma_{i j}}\left(\frac{N}{f}\right)^{n}-\frac{1}{2 G_{0}} S_{i j}^{\mathrm{eq}} .
$$

When $N \neq 0$ and the different parameters $G_{0}, \lambda$, and $\eta_{0}$ are chosen, equation (24) can be used to describe the destructive creep characteristics of soil under the condition of $\left(\sigma_{1 \max }-\sigma_{3}\right)>\sigma_{\text {er }}$. In addition, equation (24) can also be used to describe the three creep stages of soil under cyclic loading.

\section{Constitutive Equation of Soil under Triaxial Compression}

The dynamic triaxial compression test is an indoor test method for studying the creep behavior of soil. The rationality of the proposed model can be verified by the dynamic triaxial test data. Therefore, the constitutive equation of soil under triaxial compression is obtained in view of equations (15) and (24).

According to equation (4), under triaxial cyclic compression, the equivalent stress state of soil subjected to

$$
\sigma_{i j}^{\mathrm{eq}}=\left[\begin{array}{ccc}
\sigma_{\mathrm{av}} \exp \left\{\left[\frac{\left(\sigma_{1 \mathrm{max}}-\sigma_{3}\right)-\sigma_{\mathrm{cr}}}{\sigma_{\mathrm{cr}}}\right] f\right\}+\sigma_{3} & 0 & 0 \\
0 & \sigma_{3} & 0 \\
0 & 0 & \sigma_{3}
\end{array}\right],
$$

where $\sigma_{3}$ is the confining pressure acting on the specimen.

According to equation (8), the dynamic yield function under triaxial condition is

$$
\begin{aligned}
& F\left(I_{1 \mathrm{eq}}, J_{2 \mathrm{eq}}, \phi_{\mathrm{cq}}, \phi_{\mathrm{eq}}, \sigma_{\mathrm{av}}\right)=\left[\left(\alpha_{\mathrm{eq}}\left(\sigma_{1}^{\mathrm{eq}}+2 \sigma_{3}\right)+\frac{1}{\sqrt{3}}\left(\sigma_{1}^{\mathrm{eq}}-\sigma_{3}\right)-K_{\mathrm{eq}}\right)\right] \\
& \quad+\frac{1}{\sqrt{3}}\left[\left(\sigma_{1}^{\mathrm{eq}}-\sigma_{3}\right)-\sigma_{\mathrm{av}}\right] .
\end{aligned}
$$


By plugging equations (25) and (26) into equations (15) and (24), the constitutive equations of soil under triaxial compression are obtained. So, the constitutive equations of soil under triaxial compression are shown in equations (27) and (28), respectively:

$$
\begin{aligned}
\varepsilon_{11}(N)= & \frac{\sigma_{1}^{\mathrm{eq}}-\sigma_{3}}{3 G_{0} \exp \left[-\lambda(N / f)^{\lambda}\right]}+\frac{\sigma_{1}^{\mathrm{eq}}+2 \sigma_{3}}{9 K_{0} \exp \left[-\lambda(N / f)^{\lambda}\right]} \\
\Delta \varepsilon_{11}^{\mathrm{p}}(N)= & \frac{\sigma_{1}^{\mathrm{eq}}-\sigma_{3}}{3 G_{0} \exp \left[-\lambda(N / f)^{\lambda}\right]}+\left[\left(\alpha+\frac{2}{\sqrt{3}}\right)^{2} \sigma_{1}^{\mathrm{eq}}+\left(2 \alpha_{\mathrm{eq}}^{2}+\frac{2}{\sqrt{3}} \alpha_{\mathrm{eq}}-\frac{4}{3}\right) \sigma_{3}-\left(K_{\mathrm{eq}}+\frac{1}{\sqrt{3}} \sigma_{\mathrm{av}}\right)\left(\alpha_{\mathrm{eq}}+\frac{2}{\sqrt{3}}\right)\right] \\
& \frac{1}{\eta_{0} n}\left(\frac{N}{f}\right)^{n}-\frac{\sigma_{1}^{\mathrm{eq}}-\sigma_{3}}{3 G_{0}} .
\end{aligned}
$$

\section{Adaptability Verification and Example Analysis of EVPM}

\subsection{Parameter Determination and Adaptability Verification of EVPFM}

5.1.1. Determination of Parameters. 1stop is leading software for nonlinear curve fitting and comprehensive optimization analysis in the world. It has been widely recognized in the field of nonlinear regression, fitting nonlinear curve, and parameter estimation of complex engineering models. In this paper, the software was used to solve the parameters of the proposed model.

In equation (27), there are 3 parameters: $G_{0}, K_{0}$, and $\lambda$. In equation (28), there are 4 parameters: $G_{0}, \lambda, \eta_{0}$, and $n$. In order to verify the adaptability of the model, the PO (Powell Optimization) method and SA (Simulated Annealing) method in 1stop software are used to calculate the parameters of the constitutive equation for destructive and stable creep of soil under cyclic loading, respectively.

The process of solving model parameters and fitting test data is as follows. According to equation (4), the equivalent stress under different stress amplitudes was obtained. When the stable creep behavior occurs, equation (27) and the corresponding experimental data were input into the software. When the destruction creep behavior occurs, the constitutive equation (28) and the corresponding test data were input, and then, the corresponding optimization algorithm for parameter calculation was selected. Finally, the curves and parameters of the proposed model could be obtained by running the program.

5.1.2. Calculation of EVPM Parameters for Laterite Mixed with Cement. Kong et al. [30] used the British GDS dynamic triaxial test system to carry out cyclic test on laterite mixed with cement under sine-wave periodic load with frequency $f=5 \mathrm{~Hz}$; the stress level is $D=\sigma_{d} / 2 \tau_{f}\left(\tau_{f}\right.$ is the static shear strength) when testing. According to the test, the critical dynamic stress amplitudes $\sigma_{\mathrm{dc}}$ of laterite mixed with cement under confining pressure $p_{c}$ of 25,50 , and $100 \mathrm{kPa}$ are 216 , 274 , and $339 \mathrm{kPa}$ respectively; the static shear strength $\tau_{f}$ is $720 \mathrm{kPa}, 917 \mathrm{kPa}$, and $1130 \mathrm{kPa}$, respectively. The test conditions are shown in Table 1. The vibration center of the axial dynamic stress is $\sigma=p_{\mathrm{c}}+\sigma_{d}$, and the axial dynamic stress is

$$
\sigma_{1}(t)=\sigma_{3}+\sigma_{d}+\left(\frac{\sigma_{d}}{2}\right) \sin (\bowtie t)
$$

According to equation (29), it is well known that $\sigma_{1 \max }=\sigma_{3}+\sigma_{d}+\left(\sigma_{d} / 2\right)$, and the average value of the deviatoric stress under cyclic loading is $\sigma_{\mathrm{av}}=\sigma_{d}$.

Under 25,50 , and $100 \mathrm{kPa}$ confining pressure, when the critical state occurs, the average value of cyclic loading is 216 , 274, and $339 \mathrm{kPa}$; then, the critical strength $\sigma_{\mathrm{cr}}=\sigma_{\mathrm{dc}}+\left(\sigma_{\mathrm{dc}} / 2\right)$ are 314,411 , and $508.5 \mathrm{kPa}$, respectively. The corresponding $\sigma_{1 \max }$ at critical state are 457,598 , and $778 \mathrm{kPa}$, respectively.

$n$ in equation (4) takes 1 here. The critical equivalent stress $\sigma_{1}^{\mathrm{eq}}$ of soil under 25,50 , and $100 \mathrm{kPa}$ confining pressure is $243.54,324.78$, and $401.82 \mathrm{kPa}$, respectively.

According to equation (10), the equivalent internal friction angle $\phi_{\mathrm{eq}}=21.10^{\circ}$ and the equivalent cohesion $c_{\mathrm{eq}}=$ $78.42 \mathrm{kPa}$ of laterite mixed with cement can be obtained by selecting the equivalent stress state under 25 and $100 \mathrm{kPa}$ confining pressure. $\alpha_{\text {eq }}=0.12$ and $K_{\text {eq }}=76.73 \mathrm{kPa}$ can be obtained from equation (9).

According to the obtained parameters, the constitutive equation (28) of laterite mixed with cement can be further simplified to

$$
\Delta \varepsilon_{11}^{p}(N)=\frac{\left[\sigma_{1}\right]_{\mathrm{eq}}-\sigma_{3}}{3 G_{0} \exp \left[-\lambda(N / f)^{\lambda}\right]}+\frac{\left[\sigma_{1}\right]_{\mathrm{eq}}+2 \sigma_{3}}{9 K_{0} \exp \left[-\lambda(N / f)^{\lambda}\right]}+\left[1.62\left[\sigma_{1}\right]_{\mathrm{eq}}-1.17 \sigma_{3}-1.27\left(76.73+\frac{1}{\sqrt{3}} \sigma_{\mathrm{av}}\right)\right] \frac{1}{\eta_{0} n}\left(\frac{N}{f}\right)^{n}
$$


TABLE 1: Test conditions [30].

\begin{tabular}{lcccccccc}
\hline $\begin{array}{l}\text { Confining pressure } \\
(\mathrm{kPa})\end{array}$ & \multicolumn{10}{c}{ Dynamic stress amplitude $\sigma_{d}(\mathrm{kPa})$} \\
\hline 25 & 25 & 45 & 65 & 95 & 150 & 225 & 245 & 260 \\
50 & 50 & 100 & 150 & 175 & 200 & 285 & 310 & - \\
100 & 100 & 200 & 300 & 330 & 360 & 370 & 380 & 390 \\
\hline
\end{tabular}

According to the data from Table 1 and equation (4), the equivalent deviator stress $\sigma_{1}^{\mathrm{eq}}-\sigma_{3}$ under 25 and $100 \mathrm{kPa}$ confining pressure can be calculated; the results of equivalent deviator stresses under different dynamic stress amplitudes $\sigma_{d}$ are shown in Table 2 .

It can be seen from Table 2 that if $\left(\sigma_{1 \max }-\sigma_{3}\right)>\sigma_{\mathrm{cr}}$ of cyclic loading, the equivalent deviatoric stress $\sigma_{1 \mathrm{eq}}-\sigma_{3}>\sigma_{\mathrm{av}}$ obtained from equation (2). On the contrary, if $\left(\sigma_{1 \max }-\sigma_{3}\right)<\sigma_{\mathrm{cr}}, \sigma_{1 \mathrm{eq}}-\sigma_{3}<\sigma_{\mathrm{av}}$. In addition, the equivalent stress $\sigma_{\text {leq }}-\sigma_{3}$ obtained was near $\sigma_{\mathrm{av}}$ of cyclic loading, indicating that the equivalent of equation (4) is reasonable and the effect of cyclic loading on the soil can be reflected by it.

In this research, the obtained parameters of the model of soil under the confining pressure of $100 \mathrm{kPa}$ are shown in Table 3, and the comparison between model curves and test curves is shown in Figure 5.

From Figure 5 and Table 3, it can be seen that the elasticviscoplastic constitutive model based on the Bingham model can describe the stable and destructive creep behavior of soil under cyclic loading. The fitting precision of various deformation curves is good. The fitting correlation coefficient is above 0.870 and up to 0.999 under high and low dynamic stress. Therefore, the constitutive equation established in this paper can be used to reflect the various creep behavior of soil under cyclic loading.

\subsubsection{Analysis of EVPM Parameters of Laterite Mixed with} Cement. Under the confining pressure of $100 \mathrm{kPa}$, the obtained model curve is shown in Figure 5, and the fitted parameters are shown in Table 3 . By analyzing the model parameters in Table 3, it can be found that when stable creep behavior occurs, the model parameters $\lambda, K_{0}$, and $G_{0}$ decayed with the increase of $\sigma_{1}^{\mathrm{eq}}-\sigma_{3}$ (Figures 6-8) and when destructive creep behavior occurs, $\lambda, \eta_{0}$ and $G_{0}$ decreased with the increase of $\sigma_{1}^{\mathrm{eq}}-\sigma_{3}$ (Figures 9-11). When the upper limit of the cyclic loading is near the critical dynamic stress, $n$ was close to 0 , and when the cyclic load increased, $n$ was close to a fixed value. $R$ in Table 3 is correlation coefficient.

5.2. Application Analysis. From the variation of model parameters under different dynamic stress amplitudes [31-33], when the confining pressure is $100 \mathrm{kPa}$, it is known that the value of each parameter varies obviously with $\sigma_{1}^{\text {eq }}-\sigma_{3}$. According to the above analysis, it can be assumed that the parameter variation laws under any dynamic pressure and different dynamic stress are consistent with $100 \mathrm{kPa}$, but the numerical values are inconsistent. Under different confining pressures, the values of each parameter can be determined by a set of tests under specific confining pressures. Consequently, it can be assumed that the model parameters under a certain confining pressure with different dynamic stress amplitudes are determined by equations (31)-(33) when a stable creep behavior occurs:

$$
\begin{aligned}
K_{0} & =1.17 \times 10^{5}\left(\sigma_{1}^{\mathrm{eq}}-\sigma_{3}\right)^{-0.259} \times \beta_{1}^{s}\left(\sigma_{1}^{\mathrm{eq}}, \sigma_{2}, \sigma_{3}\right), \\
G_{0} & =1.770 \times 10^{16} \times\left(\sigma_{1}^{\mathrm{eq}}-\sigma_{3}\right)^{-0.216} \times \beta_{2}^{s}\left(\sigma_{1}^{\mathrm{eq}}, \sigma_{2}, \sigma_{3}\right), \\
\lambda & =0.210 \times\left(\sigma_{1}^{\mathrm{eq}}-\sigma_{3}\right)^{-0.033} \times \beta_{3}^{\mathrm{s}}\left(\sigma_{1}^{\mathrm{eq}}, \sigma_{2}, \sigma_{3}\right) .
\end{aligned}
$$

In equations (31)-(33), $\beta_{1}^{\mathrm{s}}, \beta_{2}^{\mathrm{s}}$, and $\beta_{3}^{\mathrm{s}}$ values can be obtained by plugging parameters $K_{0}, G_{0}$, and $\lambda$ determined by a group test data from stable creep into equations (31)-(33). Of course, in order to get more accurate values, it can be determined by combining more test data.

When destructive creep occurs, the parameters $G_{0}, \lambda$, and $\eta_{0}$ are determined by the following equations (34)-(36):

$$
\begin{aligned}
& G_{0}=1.425 \times 10^{16} \times\left(\sigma_{1}^{\mathrm{eq}}-\sigma_{3}\right)^{-4.840} \times \beta_{1}^{\mathrm{f}}\left(\sigma_{1}^{\mathrm{eq}}, \sigma_{2}, \sigma_{3}\right), \\
& \lambda=1.159 \times\left(\sigma_{1}^{\mathrm{eq}}-\sigma_{3}\right)^{-3.795} \times \beta_{2}^{\mathrm{f}}\left(\sigma_{1}^{\mathrm{eq}}, \sigma_{2}, \sigma_{3}\right), \\
& \eta=8.285 \times 10^{76}\left(\sigma_{1}^{\mathrm{eq}}-\sigma_{3}\right)^{-28.241} \times \beta_{3}^{\mathrm{f}}\left(\sigma_{1}^{\mathrm{eq}}, \sigma_{2}, \sigma_{3}\right)
\end{aligned}
$$

In equations (34)-(36), $\beta_{1}^{\mathrm{f}}, \beta_{2}^{\mathrm{f}}$, and $\beta_{3}^{\mathrm{f}}$ values can be obtained by plugging parameters $G_{0}, \lambda$, and $\eta_{0}$ determined by a group test data from destructive creep into equations (31)-(33). Of course, in order to get more accurate values, it can be determined by combining a set of test data.

When the upper limit of stress is close to the critical dynamic stress, the parameter $n$ value tends to 0 . Under the other different conditions of $\sigma_{d}$, it is temporarily determined to be 1.350 in combination with Table 3 , but the specific change law of $n$ should be further studied in combination with a large number of experiments.

In this paper, when stable creep occurs, $\beta_{1}^{s}=1 / 3.44$, $\beta_{2}^{\mathrm{s}}=1 / 1.92$, and $\beta_{3}^{\mathrm{s}}=1 / 0.946$ are obtained by plugging the parameter $K_{0}, G_{0}$, and $\lambda$ value under the dynamic stress amplitude of $25 \mathrm{kPa}$ and $25 \mathrm{kPa}$ confining pressure into equations (31)-(33). When calculating, because the part result of calculation is slightly smaller, $s$ is taken as $1 / 4$. Finally, the parameters $K_{0}, G_{0}$, and $\lambda$ under dynamic stress amplitude of $45,65,95,150$, and $225 \mathrm{kPa}$ are calculated in Table 4 . The deformation under dynamic stress amplitudes $45,65,95,150$, and $225 \mathrm{kPa}$ is predicted by using the calculated parameters. The predicted results are compared with the experimental results, as shown in Figure 12, when stable creep behavior occurs.

When the destructive creep behavior occurs, in this paper, the parameter value of $\beta_{1}^{\mathrm{f}}, \beta_{2}^{\mathrm{f}}$, and $\beta_{3}^{\mathrm{f}}$ can be obtained by combining the experimental parameter value under confining pressure $25 \mathrm{kPa}$ and dynamic stress amplitude $245 \mathrm{kPa}$ with equations (32)-(34). $\beta_{1}^{\mathrm{f}}=0.126, \beta_{2}^{\mathrm{f}}=0.302$, and $\beta_{3}^{\mathrm{f}}=$ $6.476 \times 10^{-5}$ are obtained by plugging the parameter $K_{0}, \eta_{0}$, 
TABLe 2: The equivalent deviator stress of cyclic loading.

\begin{tabular}{|c|c|c|c|c|c|c|c|c|}
\hline Confining pressure $(\mathrm{kPa})$ & & & & quivalen & $-\sigma_{3}(\mathrm{kF}$ & & & \\
\hline 25 & 16.10 & 30.47 & 45.81 & 72.52 & 130.14 & 234.18 & 266.74 & 293.15 \\
\hline 100 & 70.46 & 162.12 & 282.53 & 326.72 & 371.33 & 387.42 & 403.50 & 422.48 \\
\hline
\end{tabular}

TABLE 3: EVPM parameters of laterite mixed with cement under $100 \mathrm{kPa}$ confining pressure [30].

\begin{tabular}{lccccc}
\hline$\sigma_{d}(\mathrm{kPa})$ & $G_{0}(\mathrm{kPa})$ & $K_{0}(\mathrm{kPa})$ & $\lambda$ & $\eta_{0}(\mathrm{kPa} \cdot \mathrm{sn})$ & $n$ \\
\hline 100 & $7.113 \times 1015$ & $3.969 \times 104$ & 0.184 & & 0.870 \\
200 & $5.735 \times 1015$ & $2.918 \times 104$ & 0.176 & & 0.892 \\
300 & $5.472 \times 1015$ & $3.000 \times 104$ & 0.179 & & 0.893 \\
330 & $4.960 \times 1015$ & $2.510 \times 104$ & 0.172 & & 0.866 \\
360 & $3.348 \times 103$ & & 0.197 & $2.210 \times 107$ & -0.003 \\
370 & $4.158 \times 103$ & & 0.185 & $6.793 \times 106$ & 1.358 \\
380 & $3.702 \times 103$ & 0.157 & $1.917 \times 106$ & 0.999 \\
390 & $2.679 \times 103$ & & 0.116 & $6.035 \times 105$ & 1.340 \\
\hline
\end{tabular}

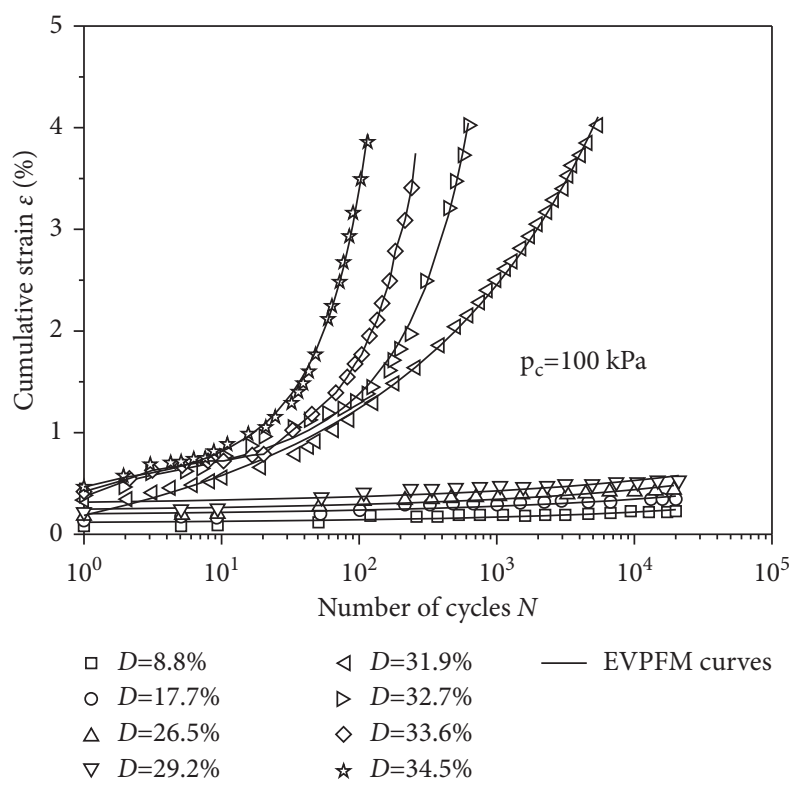

FIgURE 5: Fitting the curves of laterite mixed with cement [30] under the confining pressure of $100 \mathrm{kPa}$ by EVPFM.

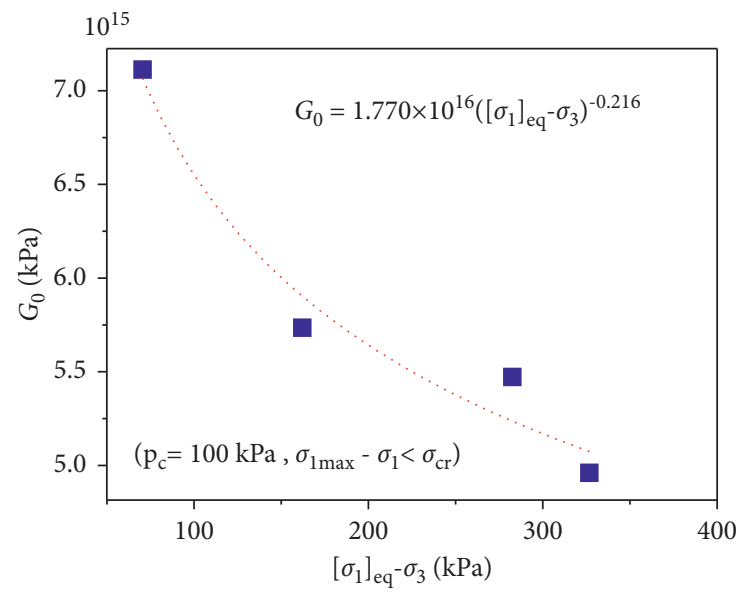

Figure 6: Relationship between $G_{0}$ and $\sigma_{1}^{\mathrm{eq}}-\sigma_{3}$ for stable creep. 


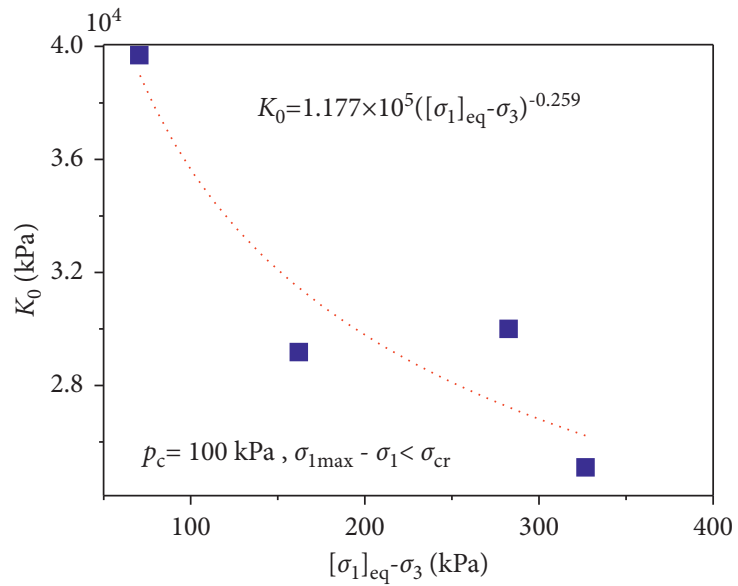

Figure 7: Relationship between $K_{0}$ and $\sigma_{1}^{\mathrm{eq}}-\sigma_{3}$ for stable creep.

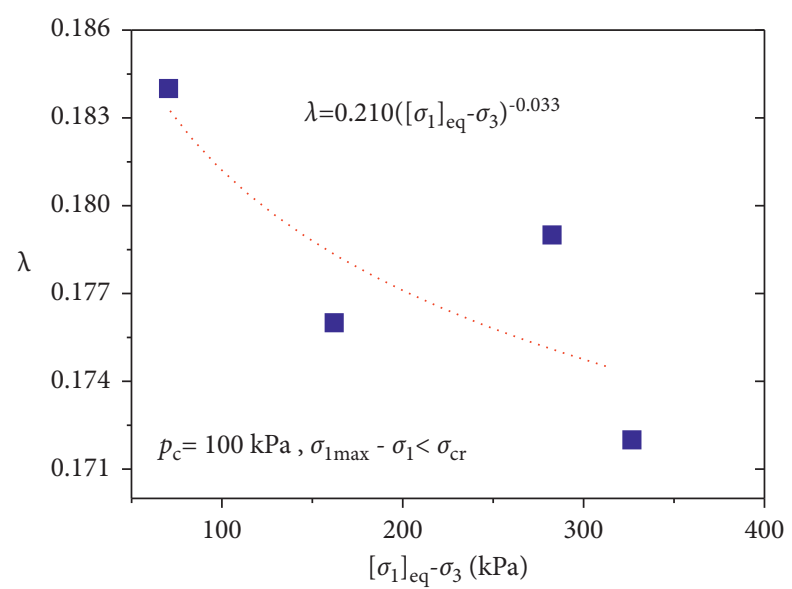

FIgURE 8: Relationship between $\lambda$ and $\sigma_{1}^{\mathrm{eq}}-\sigma_{3}$ for stable creep.

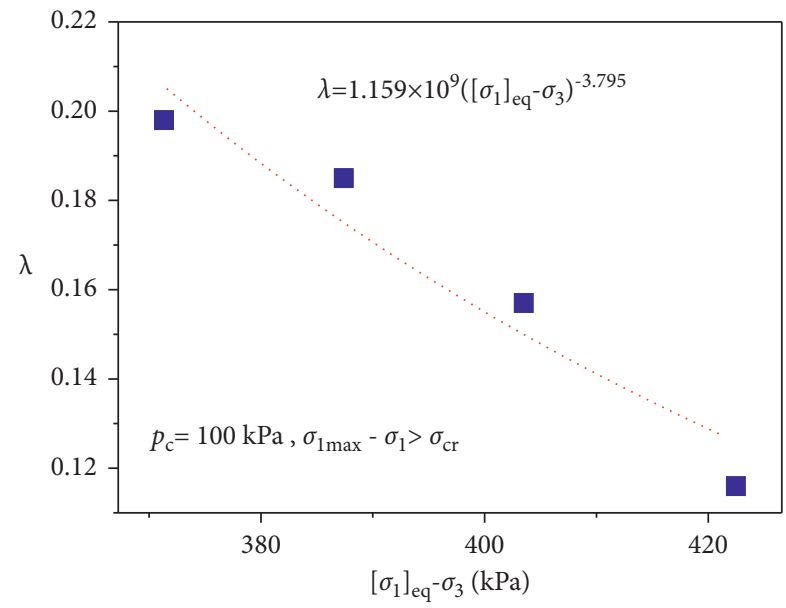

Figure 9: Relationship between $\lambda$ and $\sigma_{1}^{\mathrm{eq}}-\sigma_{3}$ for destructive creep.

and $\lambda$ value under the dynamic stress amplitude of $25 \mathrm{kPa}$ and $25 \mathrm{kPa}$ confining pressure into equations (32)-(34). According to these obtained parameters, the creep of soil

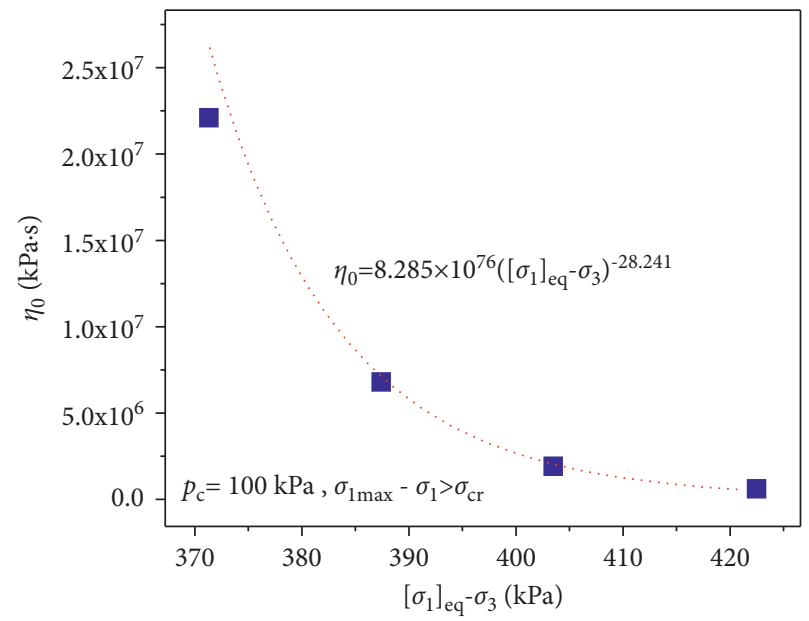

FIgURE 10: Relationship between $\eta_{0}$ and $\sigma_{1}^{\text {eq }}-\sigma_{3}$ for destructive creep.

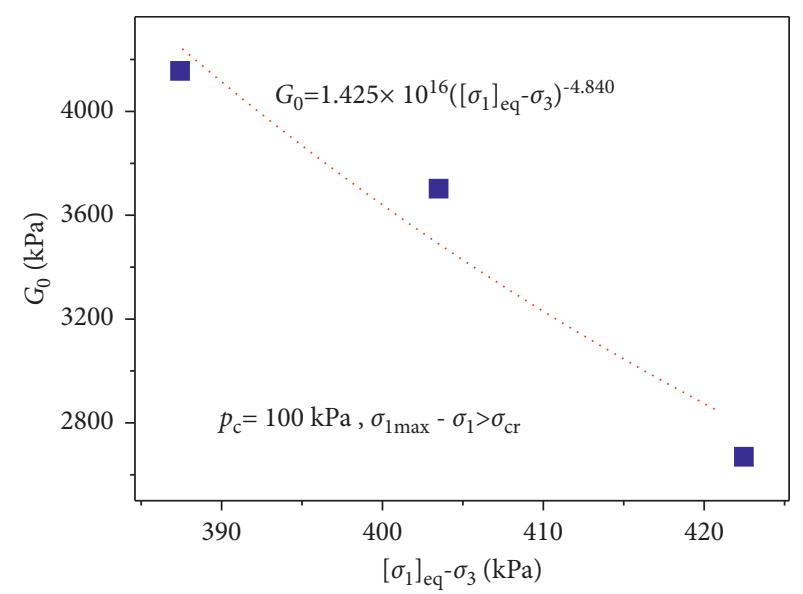

FIgURE 11: Relationship between $G_{0}$ and $\sigma_{1}^{\text {eq }}-\sigma_{3}$ for destructive creep.

under cyclic loading with a stress amplitude of $260 \mathrm{kPa}$ is calculated, and the predicted results are compared with the experimental results, as shown in Figure 13. 
TABLE 4: EVPM parameters of laterite mixed with cement under $25 \mathrm{kPa}$ confining pressure [30].

\begin{tabular}{lccccc}
\hline$\sigma_{d}(\mathrm{kPa})$ & $G_{0}(\mathrm{kPa})$ & $K_{0}(\mathrm{kPa})$ & $\lambda$ & $\eta_{0}\left(\mathrm{kPa} \cdot \mathrm{s}^{\mathrm{n}}\right)$ & $n$ \\
\hline 25 & $5.045 \times 10^{15}$ & $1.665 \times 10^{4}$ & 0.204 & Remark \\
45 & $4.406 \times 10^{15}$ & $1.413 \times 10^{4}$ & 0.200 & & Test data \\
65 & $4.036 \times 10^{15}$ & $1.270 \times 10^{4}$ & 0.197 & & \\
95 & $3.656 \times 10^{15}$ & $1127 \times 10^{4}$ & 0.193 & & \\
150 & $3.219 \times 10^{15}$ & $9.709 \times 10^{3}$ & 0.190 & & -0.009 \\
225 & $2.836 \times 10^{15}$ & $8313 \times 10^{3}$ & 0.186 & & Test data \\
245 & 3254 & & 0.216 & $9.160 \times 10^{6}$ & Calculation \\
260 & 2057 & & 0.152 & $6.305 \times 10^{5}$ & 1.350 \\
\hline
\end{tabular}

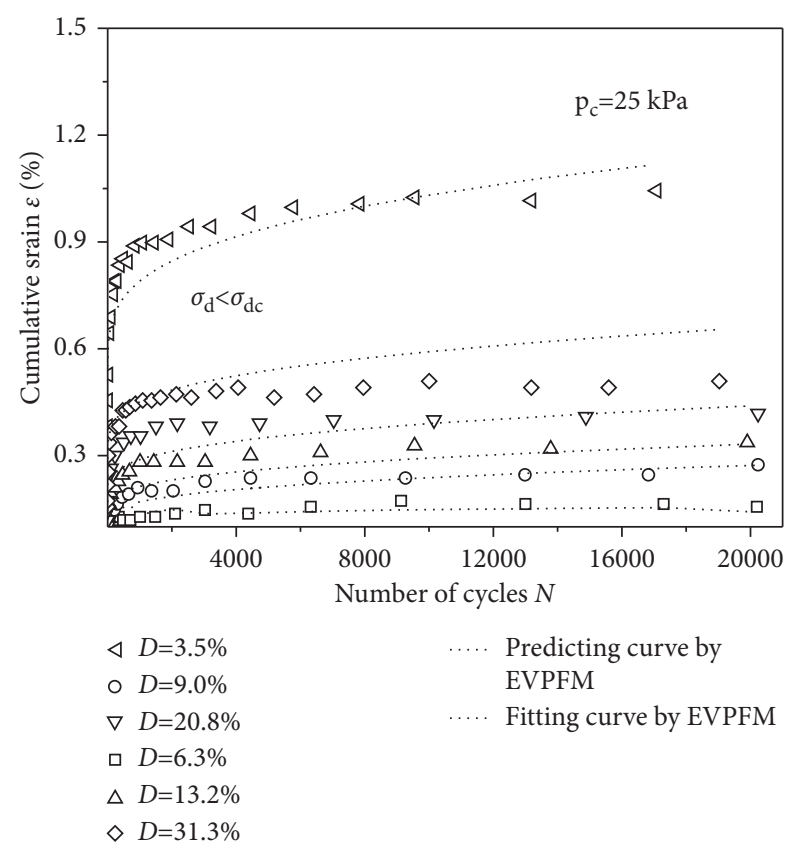

FIGURE 12: Comparison between model predictive value and test data of laterite mixed with cement [30].

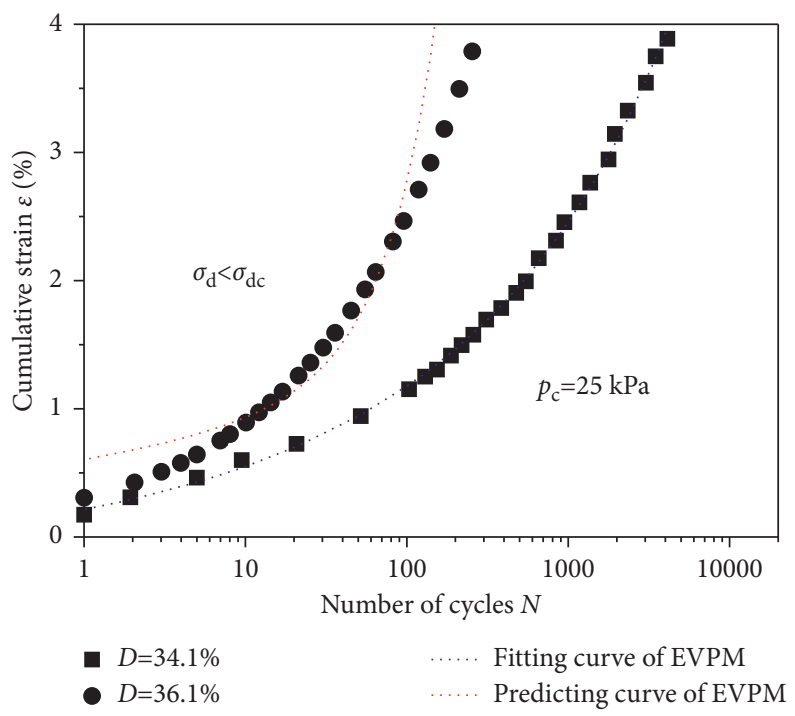

FIGURE 13: Comparison between model predictive value and test data of laterite mixed with cement [30] when destructive deformation occurs. 
The calculation results of soil deformation under confining pressure $25 \mathrm{kPa}$ show that the proposed EVPM can predict the deformation of soil under cyclic loading. There is a certain error between the calculated value of the model and the experimental value. The main reason for the error is that the experimental data are few, which leads to the inaccuracy of the changing rules of the parameters and the calculation error. Further research is needed in combination with experiments. However, the calculated results of the model are roughly consistent with the experimental data, which further illustrates the feasibility of the model.

\section{Conclusions}

In this paper, the elastic-viscoplastic model of soil under cyclic loading is established based on the Bingham model and the yield criterion of soil under equal amplitude cyclic loading is proposed. The major findings are summarized as follows:

(1) Cyclic loading is simplified equivalently; a dynamic yield criterion of soil under cyclic loading is proposed in view of the simplified load. Based on the improved Bingham model, a EVPFM of soil is established by using the flow criterion related to the dynamic yield criterion. Meanwhile, the parameters of the model are determined and the adaptability of the model is verified.

(2) The stable and destructive creep behavior of soil under cyclic loading can be reflected by the established EVPM, and the relevant parameters in the model can also be easily obtained by numerical methods.

(3) When the peak deviatoric stress $\sigma_{1 \max }-\sigma_{3}$ of periodic load is smaller than the critical dynamic stress $\sigma_{\text {cr }}$ value of soil, the model is a nonlinear model describing the stable creep behavior of the soil. Instead, the model is an EVPM describing the soil destructive creep behavior.

(4) When stable creep behavior occurs, the model has three parameters, namely, the initial value of the elastic shear fatigue coefficient $G_{0}$, the initial value of the volume fatigue coefficient $K_{0}$, and the elastic attenuation coefficient $\lambda$. All three parameters decay with increasing equivalent deviatoric stress $\sigma_{1}^{\text {eq }}-\sigma_{3}$.

(5) When destructive creep behavior occurs, the model has four parameters, $G_{0}, \lambda, \eta_{0}$, and $n$, respectively. All three parameters decay with increasing equivalent deviatoric stress $\sigma_{1}^{\text {eq }}-\sigma_{3}$. The law of change of $n$ needs to be further studied.

(6) Comparing the calculated results of strain under different dynamic stresses with the experimental results, the established model can predict the deformation of soil under cyclic loading.

\section{Data Availability}

The Microsoft Excel Worksheet data used to support the findings of this study are available from the corresponding author upon request.

\section{Conflicts of Interest}

The authors declare that there are no conflicts of interest.

\section{Acknowledgments}

This work was supported by National Key Research and Development Project (Grant no. 2020YFB1600102) and the Fund of Luoyang Tecfure Municipal Engineering Co., LTD. (Grant no. 8521005608).

\section{References}

[1] C. Shi, X. Cai, X. Yi, T. Wang, and J. Yang, "Fatigue crack density of asphalt binders under controlled-stress rotational shear load testing," Construction and Building Materials, vol. 272, p. 121899, 2021.

[2] H. Cai, Y. Cui, and Y. Lu, "Simulation of loess behaviours under cyclic loading," Chinese Journal of Rock Mechanics and Engineering, vol. 24, no. 23, pp. 4273-4281, 2005, (in Chinese).

[3] "Editorial department of China journal of highway and transport. "Review on China's tunnel engineering research: 2015," China Journal of Highway and Transport, vol. 28, no. 5, pp. 1-65, 2015, (in Chinese).

[4] X. Ding, L. Chen, T. Ma et al., "Laboratory investigation of the recycled asphalt concrete with stable crumb rubber asphalt binder," Construction and Building Materials, vol. 203, pp. 552-557, 2019.

[5] Editorial department of China journal of highway and transport, "Review on China's pavement engineering Research.2020," China Journal of Highway and Transport, vol. 33, no. 10, pp. 1-66, 2020.

[6] X. Liu, G. Yang, and W. Fang, "Critical dynamic stress of red clay and replacement thickness of ballastless track cutting bed of high-speed railways," Chinese Journal Of Geotechnical Engineering, vol. 33, no. 3, pp. 348-353, 2011, (in Chinese).

[7] J. Wang, X. Ling, Q. Li, F. Zhang, and Y. Li, "Accumulated permanent strain and critical dynamic stress of frozen silty clay under cyclic loading," Cold Regions Science and Technology, vol. 153, pp. 130-143, 2018.

[8] J. Zhu, T. Ma, and Z. Dong, "Evaluation of optimum mixing conditions for rubberized asphalt mixture containing reclaimed asphalt pavement," Construction and Building Materials, vol. 234, Article ID 117426, 2020.

[9] T. Chen, T. Ma, X. Huang, S. Ma, F. Tang, and S. Wu, "Microstructure of synthetic composite interfaces and verification of mixing order in cold-recycled asphalt emulsion mixture," Journal of Cleaner Production, vol. 263, Article ID 121467, 2020.

[10] Q.-L. Deng and X.-W. Ren, “An energy method for deformation behavior of soft clay under cyclic loads based on dynamic response analysis," Soil Dynamics and Earthquake Engineering, vol. 94, pp. 75-82, 2017.

[11] M. Huang and X. Liu, "Creep settlement model of high filled embankment after construction under traffic loads," Journal of PLA University of Science and Technology, vol. 12, no. 1, pp. 54-58, 2011, (in Chinese).

[12] H. Zhang, X. Bian, and Y. Wang, "Visco-elastic-plastic model of permanent deformation of subgrade soils under repeated load," Journal of Chang'an University (Natural Science Edition), vol. 30, no. 2, pp. 29-33, 2010, (in Chinese).

[13] S. Pu, J. Rao, and K. Yang, "Deformation characteristics of soil under cyclic loading," Rock and Soil Mechanics, vol. 38, no. 11, pp. 3262-3270, 2017, (in Chinese). 
[14] Z. Chen, S. Pu, and J. Rao, "Visco-elastic-plastic fatigue constitutive model for soil under traffic loading," Railway standard design, vol. 63, no. 1, pp. 69-73, 2018, (in Chinese).

[15] A. Niemunis, T. Wichtmann, and T. Triantafyllidis, "A highcycle accumulation model for sand," Computers and Geotechnics, vol. 32, no. 4, pp. 245-263, 2005.

[16] P.-f. Jia and L.-w. Kong, "Modeling of ratcheting accumulation of secondary deformation due to stress-controlled highcyclic loading in granular soils," Journal of Central South University, vol. 22, no. 6, pp. 2306-2315, 2015.

[17] B. O. Hardin and V. P. Drnevich, "Shear modulus and damping in soils: measurement and parameter effects (terzaghi leture)," Journal of the Soil Mechanics and Foundations Division, vol. 98, no. 6, pp. 603-624, 1972.

[18] C. Monismith, N. Ogaw, and C. Freeme, "Permanent deformation characteristics of subgrade soils due to repeated loading," Transportation Research Record, vol. 537, pp. 1-17, TRB, Washington, DC, USA, 1975.

[19] X. Ren, Q. Xu, and J. Teng, "A novel model for the cumulative plastic strain of soft marine clay underlong-termic loads," Journal of Mountain Science, vol. 14, no. 11, pp. 2348-2358, 2017.

[20] X.-W. Ren, Y.-Q. Tang, J. Li, and Q. Yang, “A prediction method using grey model for cumulative plastic deformation under cyclic loads," Natural Hazards, vol. 64, no. 1, pp. 441-457, 2012.

[21] Y. Sun, "Fractional order modelling of the cumulative deformation of granular soils under cyclic loading," Acta Mechanica Solida Sinica, vol. 28, no. 6, 2015.

[22] J. Li, “Extension of druker-prager's failure criterion," Journal of Gezhouba Institute of Hdroelctric Engineering, vol. 16, no. 1, pp. 27-30, 1994, in Chinese.

[23] J.-T. Guo, Z.-M. Zhang, Y.-L. Tang, and J. Ji, "A simplified viscoelastic solution of the frost heaving force of cavity water behind tunnel linings," Advances in Civil Engineering, vol. 2020, Article ID 8857580, 8 pages, 2020.

[24] K. Mu, A. Guo, and W. Bai, "Experimental Study on Dynamic Properties of Red Clay in Guang Xi under cyclic Loading," China Earthquake Engineering Joural, vol. 37, no. 2, pp. 488-491, 2015, in Chinese.

[25] X. Lai, W. Jian, and X. Xu, "Exprimental study on dynamic characteristics of muddy soil in Fuzhou," Journal of Engineering Geology, vol. 24, no. 6, pp. 1303-1307, 2016, in Chinese.

[26] J. Guo, C. Qiao, and C. Xu, "The Kelvin-Voigt rheological model based on fractional calculus," China Railway Science, vol. 30 , no. 4 , pp. $2-5,2009$, in Chinese.

[27] H. Schiessel, R. Metzler, A. Blumen, and T. F. Nonnenmacher, "Generalized viscoelastic models: their fractional equations with solutions," Journal of Physics A: Mathematical and General, vol. 28, no. 23, pp. 6567-6584, 1995.

[28] J. Sun, Rheology of Rock and Soil Materials and its Engineering Application, China architecture and building press, "Beijing, China, 1999, in Chinese.

[29] T. Yang, Viscoelastic Mechanics,", Central China University of science and Technology Press, Wuhan, China, 1990, in Chinese.

[30] X. Kong, G. Jang, and Z. Wang, "Mechanical properties and micro-structure characteristic of laterite mixed with cement," Hydrogeology \& Engineering Geology, vol. 39, no. 4, pp. 76-87, 2012, in Chinese.

[31] W. Zhang, J. Ji, Y. Gao, X. Li, and C. Zhang, "Spatial variability effect of internal friction angle on the post-failure behavior of landslides using a random and non-Newtonian fluid based
SPH method," Geoscience Frontiers, vol. 11, no. 4, pp. 1107-1121, 2020.

[32] S. shan, X. Pei, and W. Zhan, "Estimating deformation modulus and bearing capacity of deep soils from dynamic penetration test," Advances in Civil Engineering, vol. 2021, Article ID 1082050, 13 pages, 2021.

[33] Y. Zhang, T. Ma, M. Ling, D. Zhang, and X. Huang, "Predicting dynamic shear modulus of asphalt mastics using discretized-element simulation and reinforcement mechanisms," Journal of Materials in Civil Engineering, vol. 31, no. 8, Article ID 04019163, 2019. 